\title{
Study the Migration Process of Chemical Substances through the Packaging/Food Interface during Microwave Treatment
}

\author{
Fang Duan, ${ }^{1,2}$ Ming-qing Chen, ${ }^{1,2}$ Yong Zhu, ${ }^{3}$ Hui Zhang, ${ }^{4}$ and Jing Zhang ${ }^{4}$ \\ ${ }^{1}$ School of Chemistry and Materials Engineering, Jiangnan University, Wuxi 214122, China \\ ${ }^{2}$ The Key Laboratory of Food Colloids and Biotechnology, School of Chemical and Material Engineering, \\ Ministry of Education, Jiangnan University, Wuxi 214122, China \\ ${ }^{3}$ Packaging Engineering Institute, Jinan University, Zhuhai 519070, China \\ ${ }^{4}$ Jiangyin Propack Packing Co., Ltd., Jiangyin 214433, China
}

Correspondence should be addressed to Ming-qing Chen; mqsytu1@126.com

Received 5 May 2013; Accepted 17 May 2013

Academic Editor: Jun Wang

Copyright (C) 2013 Fang Duan et al. This is an open access article distributed under the Creative Commons Attribution License, which permits unrestricted use, distribution, and reproduction in any medium, provided the original work is properly cited.

The diffusion of chemical substances from packaging into food endangers people's health. The migration amount of the chemical substances increases with the time and temperature, but the diffusion process for different kinds of packaging materials differs much. Most recently, the research community showed a renewed interest on the diffusion process of chemical substances through packaging/food interface during microwave treatment. In this study, the diffusion coefficient model is suggested and then the migration process is studied based on Fick's diffusion law. The results are finally compared with the experimental data, showing good agreement.

\section{Introduction}

Mathematical modeling is widely applied for studying the complex migration process of chemical substances from packaging into food [1-3]. The experiment methods as well as the modeling tools are studied thoroughly [4]. However, few works were reported on modeling the diffusion process during microwave treatment [5-7] though food is often microwave-heated directly inside the polymer package, which may accelerate the migration process. It is desirable to derive a mathematical model for the migration process of chemical substances from packaging into food during microwave treatment.

\section{Mathematical Modeling}

To derive the mathematical model, some assumptions are suggested: (1) the contaminant is well distributed in the packaging, while there isno contamination in the food initially; (2) the contaminant transfers through food/packaging interface with no block; (3) the migration process is unidirectional from packaging into food; and (4) the partition factor of the contaminant is taken as 1 at the interface of packaging and food.

By applying Fick's second law of diffusion [8], the diffusion of chemical substances can be described as

$$
\frac{\partial C}{\partial t}=D(t) \frac{\partial^{2} C}{\partial x^{2}}
$$

where $C$ is the concentration of a migrant in a food contact polymer at time $t$ at a distance $x$ from the origin of the $x$-axis (for single-sided contact) and $D$ is the diffusion coefficient in the polymer.

The initial condition and boundary conditions are given separately in (2) and (3) (4):

$$
\begin{gathered}
C=C_{0}, \quad 0<x<L_{p}, \quad t=0, \\
\frac{\partial C}{\partial x}=0, \quad x=0, \quad t>0, \\
C=0, \quad x=L_{p}, \quad t>0,
\end{gathered}
$$

where $C_{0}$ represents initial concentration of contaminant in packaging and $L_{p}$ defines the thickness of polymer. 
Apply the variable separation approach (VSA), and set

$$
C(x, t)=X(x) T(t)
$$

The following equations are obtained:

$$
\begin{gathered}
T=\exp \left(-\lambda^{2} \int_{0}^{t} D(t) d t\right), \\
X=A \sin \lambda x+B \cos \lambda x
\end{gathered}
$$

From (6), we can get

$$
C=\sum_{m=1}^{\infty}\left(A_{m} \sin \lambda_{m} x+B_{m} \cos \lambda_{m} x\right) \exp \left(-\lambda^{2} \int_{0}^{t} D(t) d t\right)
$$

Substituting (2) (4) into (7) leads to

$$
\begin{aligned}
C=\frac{4 C_{0}}{\pi} \sum_{n=0}^{\infty} & \frac{(-1)^{n}}{2 n+1} \exp \left(-\frac{(2 n+1)^{2} \pi^{2} \int_{0}^{t} D(t) d t}{4 L_{p}^{2}}\right) \\
& \times \cos \frac{(2 n+1) \pi x}{2 L_{p}},
\end{aligned}
$$

from which the migration amount of chemical substances can be calculated by

$$
M_{F, t}=\int_{0}^{t} A D(t) \frac{2 C_{0}}{L_{p}} \sum_{n=0}^{\infty} \exp \left(-\frac{(2 n+1)^{2} \pi^{2} \int_{0}^{t} D(t) d t}{4 L_{p}^{2}}\right) d t
$$

And as suggested in [9], the relationship between the temperature and time during microwave treatment can be approximately modeled by a linear equation,

$$
T(t)=k_{1} t+k_{2}
$$

The relationship between the absorbed power and the temperature variation can be written as

$$
P_{\text {absorb }} t=c m \Delta T \text {. }
$$

Substituting (10) into (11) leads to

$$
T(t)=\frac{P_{\mathrm{absorb}} t}{\mathrm{~cm}}+T_{0}
$$

where $c$ and $m$ are separately the specific heat and mass of the food, respectively; $T_{0}$ is the initial temperature of the food.

By introducing the Arrhenius' law, the diffusion coefficient is related to the temperature as in [10]

$$
D(t)=D_{0} \exp \left(-\frac{E}{R T}\right)
$$

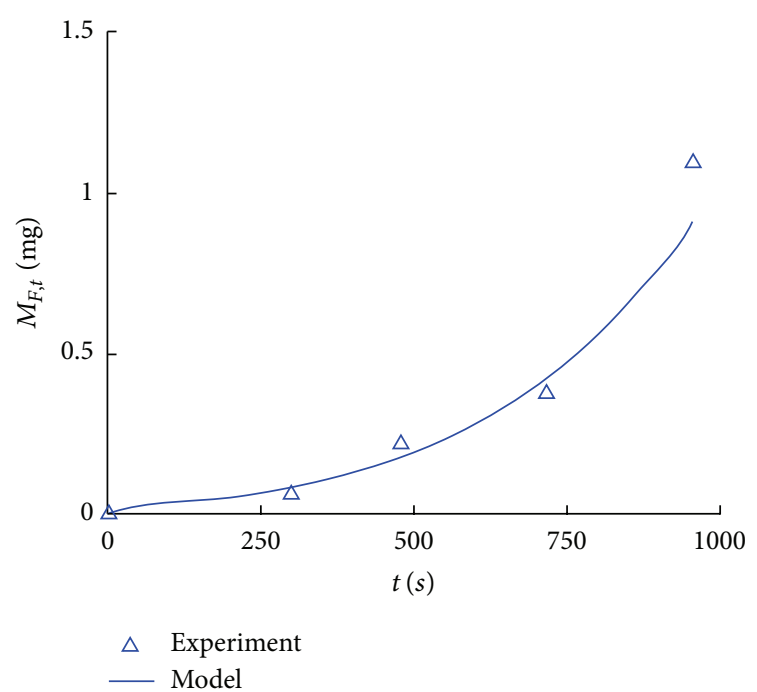

FIGURE 1: Comparison of the experiment data and model results for migration of antioxidant 1076 from HDPE film into olive oil with microwave input power of $200 \mathrm{~W}$. to

Substituting (12) into (13) and replacing $D(t)$ in (9) lead $M_{F, t}$

$$
\begin{gathered}
=\int_{0}^{t} A D_{0} \exp \left(-\frac{E}{R((P t / c m)+T)}\right) \frac{2 C_{0}}{L_{p}} \\
\times \sum_{n=0}^{\infty} \exp \left(-\left((2 n+1)^{2} \pi^{2}\right.\right. \\
\left.\times \int_{0}^{t} D_{0} \exp (-E / R((P t / c m)+T)) d t\right) \\
\left.\times\left(4 L_{p}^{2}\right)^{-1}\right) d t
\end{gathered}
$$

Here, $A$ is the contact area between polymer packaging and food. $E$ defines the activation energy of polymer, and $R$ defines the molar constant of chemical substance.

\section{Results and Discussion}

The suggested model previously mentioned provides us with a new mathematical method for studying the diffusion process of chemical substances from packaging into food. To check the accuracy of the proposed method, the migration experiment of antioxidant 1076 from HDPE film into the fatty food stimulants (olive oil) through single contact is conducted and compared with the theoretical prediction. The contact area between polymer packaging and food $(A)$ is $45 \mathrm{~cm}^{2}$. The volume of fatty food simulants is $25 \mathrm{~mL}(m$ equals $20 \mathrm{~g}$ ), the parameter $c$ in (14) for the studied mixture is $2000 \mathrm{~kJ} / \mathrm{kg}$. The initial concentration of contaminant in polymer $\left(C_{0}\right)$ is $4.5 \mathrm{mg} \cdot \mathrm{cm}^{-3}$. The thickness of the film $\left(L_{p}\right)$ is $45 \mu \mathrm{m} . D_{0}$ is $10^{-4} \mathrm{~cm}^{2} / \mathrm{s}$. And the microwave input power is 
200 W. It can be seen clearly from Figure 1 that the migration amount increases sharply with the growth of treatment time, and similar conclusion is suggested by the proposed model. Moreover, good agreement can be seen between the experiment data and the model results.

\section{Conclusions}

The diffusion process of chemical substances from packaging into food during microwave treatment was studied. A mathematical model was suggested and compared with the experiment results, showing good agreement. The results show that the migration process was accelerated during microwave treatment and the strong dependence nature of migration amount on input power and treatment time was revealed. The proposed mathematical model provides the research community with a useful tool for predicting the migration process. It should be pointed out that the suggested temperature-dependent model is valid only for single-layer packaging and the migration process is unidirectional from packaging into food.

\section{Acknowledgment}

This work was supported by Fundamental Research Funds for the Central Universities (Grant no. JUSRP51302A).

\section{References}

[1] J. Brandsch, P. Mercea, M. Rüter, V. Tosa, and O. Piringer, "Migration modelling as a tool for quality assurance of food packaging," Food Additives and Contaminants, vol. 19, no. 1, pp. 29-41, 2002.

[2] T. Begley, L. Castle, A. Feigenbaum et al., "Evaluation of migration models that might be used in support of regulations for food-contact plastics," Food Additives and Contaminants, vol. 22, no. 1, pp. 73-90, 2005.

[3] M. F. Poças, J. C. Oliveira, R. Brandsch, and T. Hogg, "Analysis of mathematical models to describe the migration of additives from packaging plastics to foods," Journal of Food Process Engineering, vol. 34, no. 4, pp. 657-676, 2012.

[4] Z. W. Wang, B. Q. Sun, and Z. G. Liu, "On migration of constitutes of packaging materials," Packaging Engineering, vol. 25, no. 5, pp. 1-4, 2004.

[5] M. Sharman, C. A. Honeybone, S. M. Jickells, and L. Castle, "Detection of residues of the epoxy adhesive component bisphenol A diglycidyl ether (BADGE) in microwave susceptors and its migration into food," Food Additives and Contaminants, vol. 12, no. 6, pp. 779-787, 1995.

[6] C. Nerin and D. Acosta, "Behavior of some solid food stimulants in contact with several plastics used in microwave ovens," Journal of Agricultural and Food Chemistry, vol. 50, no. 25, pp. 74887492, 2002.

[7] J. Alin and M. Hakkarainen, "Type of polypropylene material significantly influences the migration of antioxidants from polymer packaging to food simulants during microwave heating," Journal of Applied Polymer Science, vol. 118, no. 2, pp. 1084-1093, 2010.

[8] J. Crank, The Mathematics of Diffusion, Clarendon Press, Oxford, UK, 2nd edition, 1975.
[9] M. H. Lee, Study on migration dynamics of chemical substances of plastic packaging materials during microwave treatment [M.S. thesis], Jinan University, Guangzhou, China, 2008.

[10] T. V. Naylor, "Permeation properties," Comprehensive Polymer Science, vol. 2, pp. 643-668, 1988. 


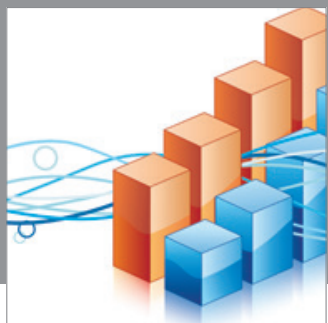

Advances in

Operations Research

mansans

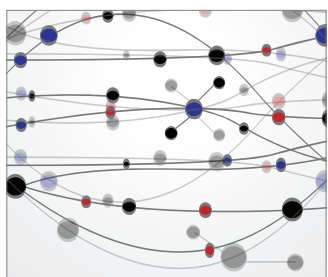

The Scientific World Journal
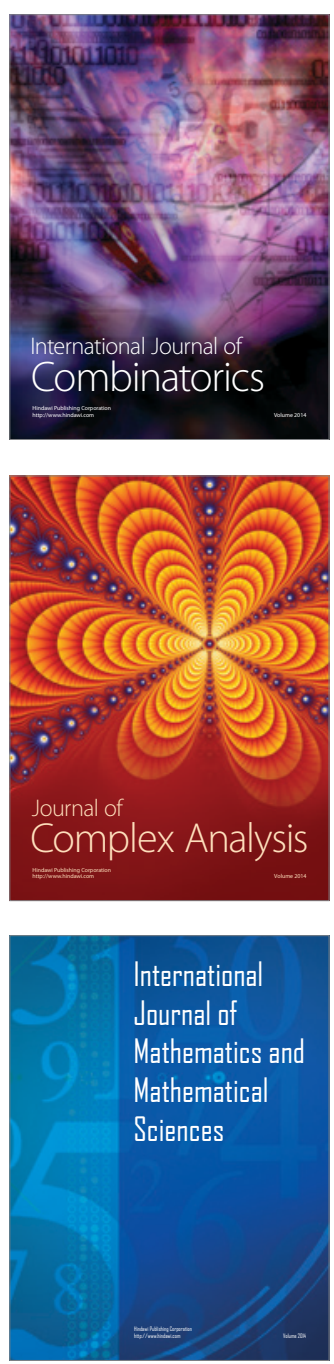
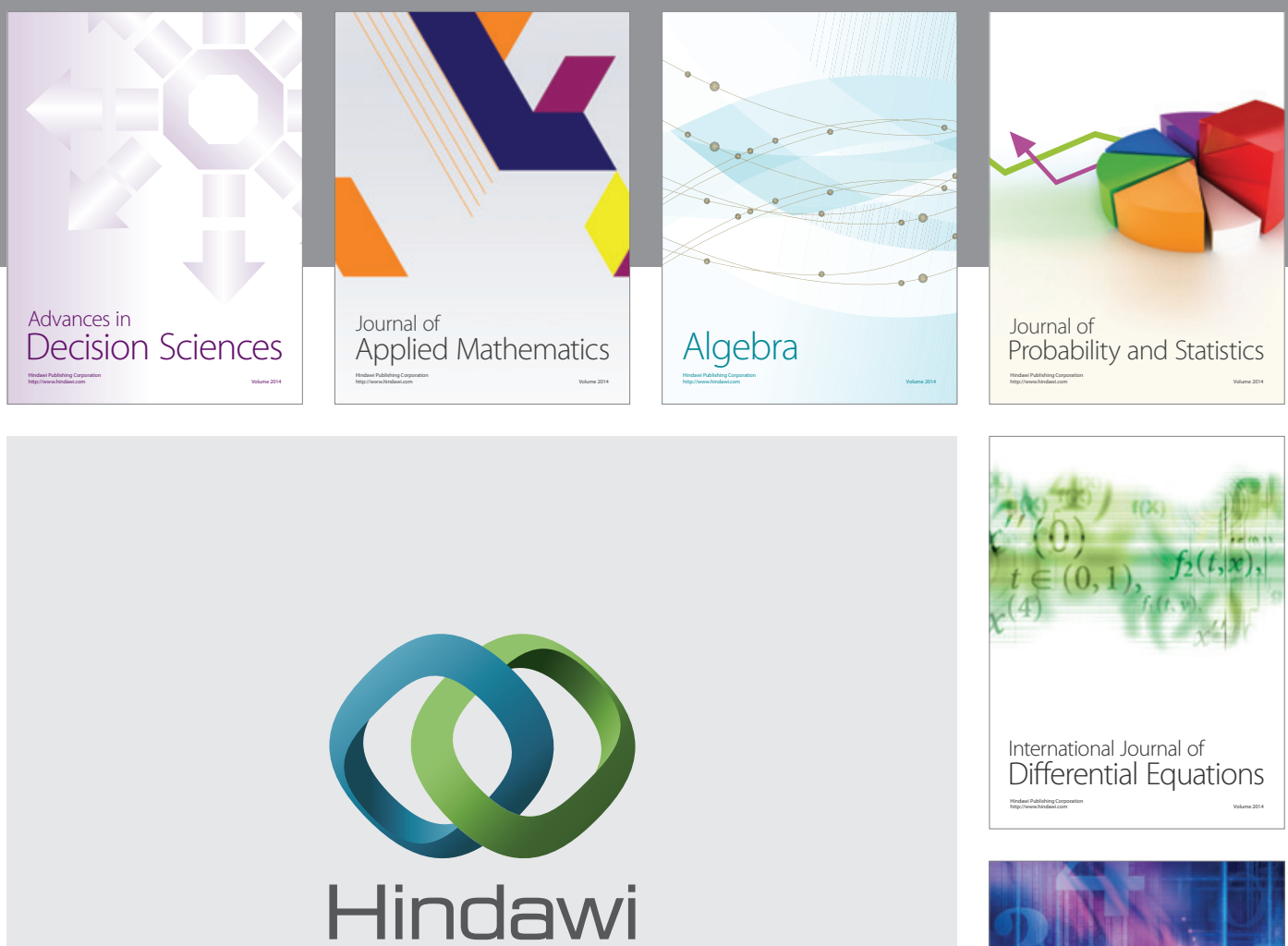

Submit your manuscripts at http://www.hindawi.com
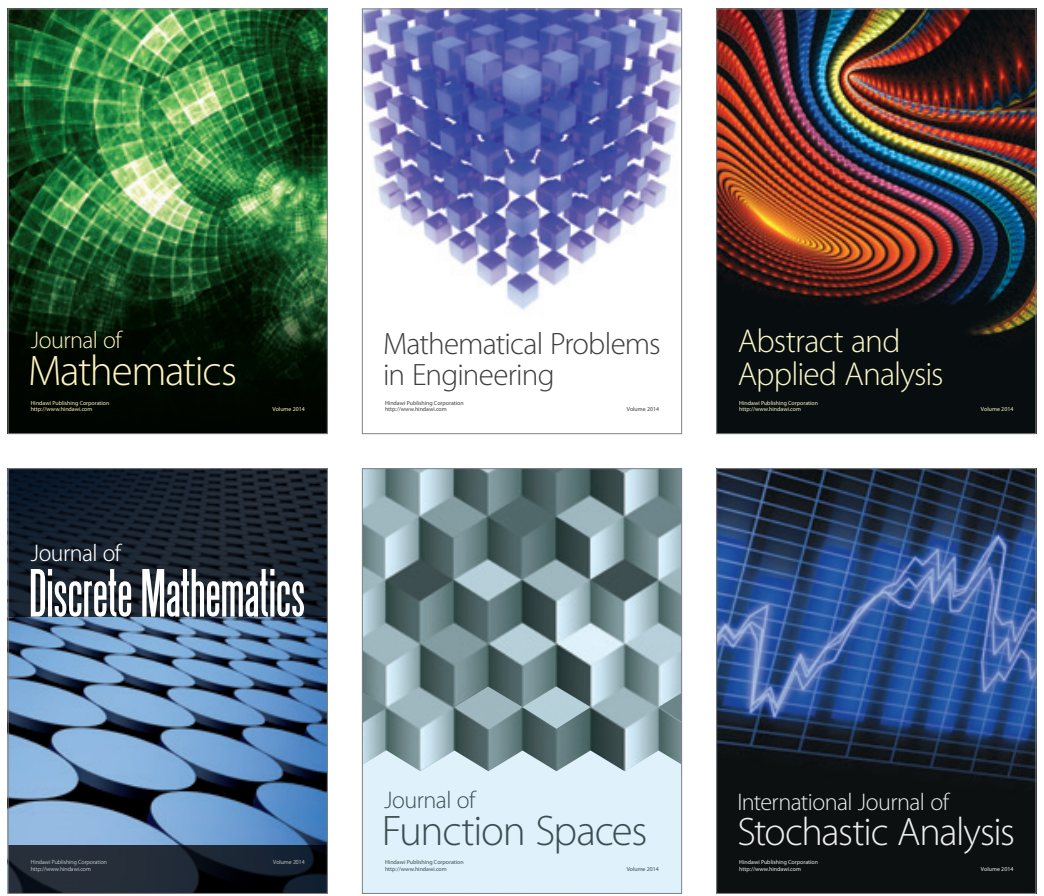

Journal of

Function Spaces

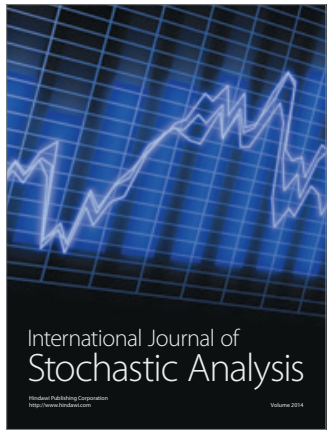

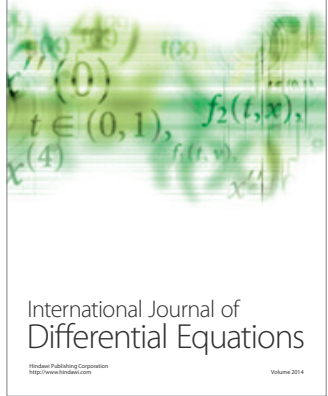
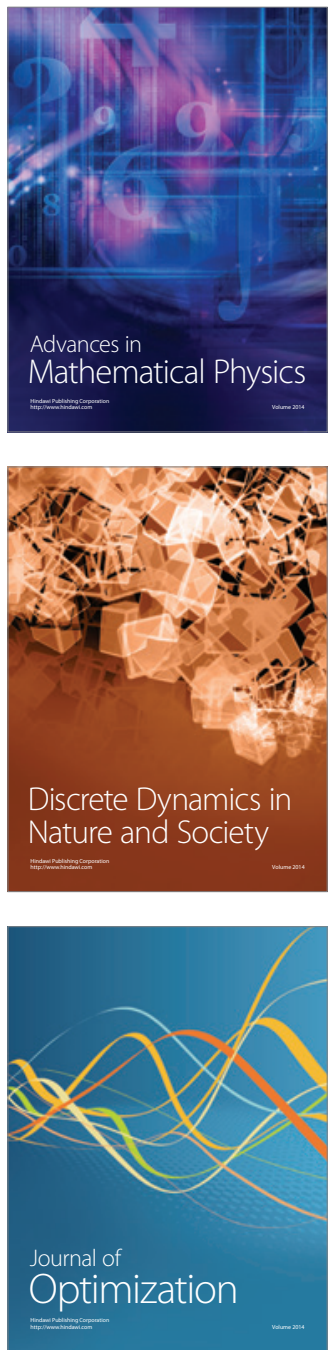